\title{
IMPACT OF OBESITY ON PULMONARY FUNCTIONS AMONG YOUNG NON-SMOKER HEALTHY FEMALE OF SHAH ALAM, MALAYSIA
}

\author{
ANIRUDDHA BHATTACHARJEE ${ }^{1 *}$, ARIITHARAN A/L THYGO0 ${ }^{1}$, SUBRAMANIAN RAMMOHAN \\ ${ }^{1}$ Department of Physiology, International Medical School, Management \& Science University, Malaysia. ${ }^{2}$ Department of Pharmacology, \\ International Medical School, Management \& Science University, Malaysia. Email: aniruddha60@gmail.com
}

Received: 10 May 2018, Revised and Accepted: 20 July 2018

\section{ABSTRACT}

Objectives: The sedentary lifestyle, physical inactivity, and unhealthy diet of Malaysian female have become important contributing factors to the rise of obesity. Studies on pulmonary function in relation to obesity are very few in Malaysia. Therefore, the study was aimed to evaluate the effect of obesity on pulmonary functions among young adult healthy female students of Shah Alam, Malaysia.

Methods: A cross-sectional comparative study was conducted in a total of 100 (50 obese and 50 non-obese) adult non-smoker healthy female students aged 18-25 years. Forced vital capacity (FVC), forced expiratory volume in $1 \mathrm{sec}\left(\mathrm{FEV}_{1}\right), \mathrm{FEV}_{1}$ as a percentage of FVC $\left(\mathrm{FEV} / \mathrm{FVC}_{1}\right)$, maximum midexpiratory flow rate (FEF 25-75\%), and peak expiratory flow rate (PEFR) were measured using a computerized spirometer. Body weight, height, waist circumference (WC), and hip circumference (HC) were measured.

Results: The mean FVC (L), FEV1 (L), FEV1/FVC ratio, FEF 25-75\% (L/s), and PEFR (L/s) of obese group were marginally lower than non-obese control group, but the differences were not statistically significant. WC and waist-hip ratio exhibited significant $(p<0.05)$ inverse correlation with all pulmonary function measurements except FEV1/FVC\%. However, body mass index had no significant correlation with any spirometric variables in studied obese females.

Conclusion: There was no significant effect of obesity on pulmonary functions in the studied Malaysian females. However, abdominal obesity had more impact on the impairment of pulmonary functions than overall relative obesity.

Keywords: Obesity, Pulmonary function test, Body mass index, Waist circumference, Waist-hip ratio.

(c) 2018 The Authors. Published by Innovare Academic Sciences Pvt Ltd. This is an open access article under the CC BY license (http://creativecommons. org/licenses/by/4. 0/) DOI: http://dx.doi.org/10.22159/ajpcr.2018.v11i10.27234

\section{INTRODUCTION}

Prevalence of overweight and obesity has reached epidemic levels in Malaysia. The rapid economic development which has taken place in Malaysia in the last quarter of the 20th century, results in nutrition transition which has become one of the predominant factor for the prevalence of increased obesity in Malaysia [1]. Malaysia has recently been ranked second highest in East and Southeast Asia in terms of being overweight [2]. The sedentary lifestyle and unhealthy diet of Malaysian have become important contributing factors to the rise of obesity. Based on the report of National Health and Morbidity Surveys in 2015, the prevalence of overweight and obesity among Malaysian adults aged 18 years and above has increased from $29.4 \%$ and $15.1 \%$ in 2011 [3] to $30.0 \%$ and $17.7 \%$ in 2015 [4].

Obesity has been associated with many common non-communicable cardiovascular and metabolic diseases such as hypertension, diabetes, and hyperlipidemia [5]. However, obese people may have higher risk of respiratory impairments also. They often feel shortness of breath, particularly during exercise, even if they have no pulmonary diseases [6]. There are several respiratory complications due to obesity. Major complications are lowering of respiratory muscle endurance, chest wall compliance, and elevated work of breathing. Expiratory reserve volume and functional residual capacity are two most common lung function test abnormalities in obesity [7] which also leads to decreased total respiratory compliance [8].

The pulmonary function tests (PFTs) are non-invasive tests which help to diagnose patients with obstructive and restrictive lung diseases. Pulmonary function parameters are influenced by both relative obesity and body fat (BF) distribution. Based on the excess BF distribution, obesity can be categorized as central pattern (which is common in men) and peripheral pattern (common in women). Body mass index (BMI) is a measure of relative adiposity, whereas waist circumference (WC) and waist-hip ratio (WHR) are considered as a measure of central obesity. Studies have shown that both obesity itself and the pattern of $\mathrm{BF}$ distribution have an independent effect on ventilatory functions [9]. Most of the previous studies on pulmonary function impairment in relation to obesity have used BMI as an obesity indicator $[10,11]$. However, the abdominal obesity markers are better predictors of pulmonary function than BMI [12]. Studies on pulmonary function in relation to obesity are scanty in Malaysia. Our recent study Bhattacharje et al. [13] showed that obesity has adverse effect on dynamic lung function parameters in young non-smoker healthy Malaysian male, and central obesity has more impact on the impairment of pulmonary functions than overall relative obesity. Therefore, the present study was aimed to evaluate the effect of obesity on dynamic lung function parameters as well as to identify the association of both relative and abdominal obesity indicators with dynamic pulmonary function parameters among young non-smoker female university students of Shah Alam, Malaysia. We hypothesized that upper BF is a better predictor of reduced pulmonary function than total body adiposity.

\section{METHODS}

This cross-sectional study was conducted in the Human Physiology Laboratory of International Medical School, Management, and Science University, Shah Alam, Malaysia. Subjects with BMI $>30 \mathrm{~kg} / \mathrm{m}^{2}$ were defined as obese [14]. 50 such obese female were identified from the student population of the management and Science University, Shah Alam Campus, Malaysia. An identical number (50) of age-matched non-obese with BMI between 18.50 and $24.99 \mathrm{~kg} / \mathrm{m}^{2}$ was taken as a 
control group. Therefore, a total of 100 (50 obese and 50 non-obese) non-smoker, healthy young female subjects were selected for the study. The study population belonged to the age group of 18-25 years and with similar socioeconomic backgrounds.

Each subject filled up one questionnaire [15] to record their personal demographic data, health status, and consent to participate in the study. The experimental protocol was explained to all the participants. Each subject signed the written informed consent form.

\section{Exclusion criteria}

Subject with symptoms of illness such as fever, cough, abdominal pain, any history of pulmonary diseases, anxious, apprehensive, doing regular exercise, and uncooperative ones was excluded from the study.

\section{Anthropometric measurements}

The body weight was measured using a balanced beam scale with an accuracy of $\pm 0.1 \mathrm{~kg}$ with the subject wearing minimum clothing, whereas body height was measured with the measuring rod attached to the balanced beam with an accuracy of $\pm 0.50 \mathrm{~cm}$. WC was measured as the smallest circumference between the ribs and the iliac crest to the nearest $0.1 \mathrm{~cm}$, while the participant was standing with the abdomen relaxed, at the end of normal expiration. Hip circumference (HC) was recorded as the maximum circumference between the iliac crest and the pubic symphysis. WHR was calculated by dividing WC by HC.

\section{Pulmonary function measurements}

The dynamic pulmonary functions were recorded using a computerized spirometer (Spirobank II MIR, Del Maggiolino 125, 00155 Roma, Italy). The spirometer was calibrated daily using a calibration syringe of 2 L. The parameters measured were forced vital capacity (FVC), forced expiratory volume in 1 sec (FEV1), FEV1 as a percentage of FVC (FEV1\%), midexpiratory flow rate (FEF 25-75\%), and peak expiratory flow rate (PEFR). All the measurements were conducted in standing posture with nose clipped [16]. These tests were recorded at noon before lunch, as expiratory flow rates are highest at noon [17]. Three satisfactory efforts were recorded for each volunteer with at least $5 \mathrm{~min}$ rest between the consecutive trials as per the standard norm [18]. All the anthropometric measurements and pulmonary function measurements were recorded in one sitting on the same day for each subject.

\section{Statistical analysis}

Student's t-test was performed to test the significance of differences between mean values of obese and control group. Pearson's product moment correlation ( $r$ ) was adopted to test the relationship of anthropometric parameters with the dynamic pulmonary function measurements in both obese and control group. The level of statistical significance was set at $\mathrm{p}<0.05$.

\section{RESULTS}

Table 1 compares the demographic and anthropometric variables of the obese and control groups. The mean BMI of the obese group was $32.3 \pm 5.23 \mathrm{~kg} / \mathrm{m}^{2}$ compared to the control group's $22.81 \pm 2.27 \mathrm{~kg} / \mathrm{m}^{2}$ and the difference was significant $(\mathrm{p}<0.001)$. The mean age of the obese and control groups was $20.6 \pm 2.08$ and $21.24 \pm 2.18$ years, respectively, suggesting that the subjects of both the studied groups (obese and non-obese) fall under same age. The mean body weight, WC, and HC of the obese students were significantly $(\mathrm{p}<0.001)$ higher compared to control group with same age, whereas WHR had no significant difference.

The comparison of dynamic pulmonary function parameters of the obese and non-obese has been depicted in Table 2 .

The mean FEV1/FVC ratio of obese subjects was $89.04 \pm 12.71 \%$, which was marginally lower than non-obese control group where the mean was $95.29 \pm 7.32 \%$ (Fig. 1), but the difference was not statistically significant $(\mathrm{p}=0.06)$.
Table 1: Physical and anthropometric characteristics of obese and non-obese (control group) healthy young female of Shah Alam, Malaysia

\begin{tabular}{llll}
\hline $\begin{array}{l}\text { Physical and } \\
\text { anthropometric } \\
\text { parameters }\end{array}$ & Mean \pm SD & \multirow{2}{*}{ p values } \\
\cline { 2 - 3 } & Obese $(\mathbf{n = 5 0 )}$ & Non-obese (n=50) & \\
\hline Age (years) & $20.68 \pm 2.08$ & $21.24 \pm 2.18$ & 0.329 \\
Height $(\mathrm{cm})$ & $160.24 \pm 8.07$ & $160.20 \pm 6.02$ & 0.98 \\
Weight $(\mathrm{kg})$ & $83.24 \pm 16.62$ & $58.64 \pm 7.20$ & $<0.001^{* *}$ \\
BMI $\left(\mathrm{kg} / \mathrm{m}^{2}\right)$ & $32.31 \pm 5.23$ & $22.81 \pm 2.27$ & $<0.001^{* *}$ \\
WC $(\mathrm{cm})$ & $100.68 \pm 11.91$ & $83.32 \pm 9.49$ & $<0.001^{* *}$ \\
HC $(\mathrm{cm})$ & $130.04 \pm 13.71$ & $103.00 \pm 8.83$ & $<0.001^{* *}$ \\
WHR & $0.78 \pm 0.05$ & $0.81 \pm 0.06$ & 0.04 \\
\hline ** &
\end{tabular}

**Highly significant $\mathrm{P}<0.001$, BMI: Body mass index, WC: Waist circumference, HC: Hip circumference, WHR: Waist-hip ratio

Table 2: Comparison of dynamic lung function parameters between obese and non-obese (control group) healthy young female of Shah Alam, Malaysia

\begin{tabular}{llllll}
\hline PFT parameters & \multicolumn{2}{c}{ obese $(\mathbf{n = 5 0 )}$} & & Non-obese $(\mathbf{n = 5 0 )}$ & \multirow{2}{*}{ Significance } \\
\cline { 2 - 4 } & Mean \pm SD & & Mean \pm SD & p values & \\
\hline FVC (L) & $2.19 \pm 0.51$ & $2.22 \pm 0.45$ & 0.812 & NS \\
FEV1(L) & $1.95 \pm 0.58$ & & $2.11 \pm 0.46$ & 0.23 & NS \\
FEV1/FVC (\%) & $89.04 \pm 12.71$ & & $95.29 \pm 7.32$ & 0.06 & NS \\
FEF 25-75\% (L/s) & $2.78 \pm 1.30$ & & $3.13 \pm 0.98$ & 0.319 & NS \\
PEFR (L/s) & $3.51 \pm 1.75$ & $4.22 \pm 1.51$ & 0.18 & NS
\end{tabular}

Student's $t$-test was used to compare the significance of difference between means; NS: Not significant, FVC: Forced vital capacity, FEV1: Forced expiratory volume in $1 \mathrm{~s}$, FEV1/FVC: FEV1 as percentage of FVC, FEF 25-75\%: Maximum midexpiratory flow rate, PEFR: Peak expiratory flow rate

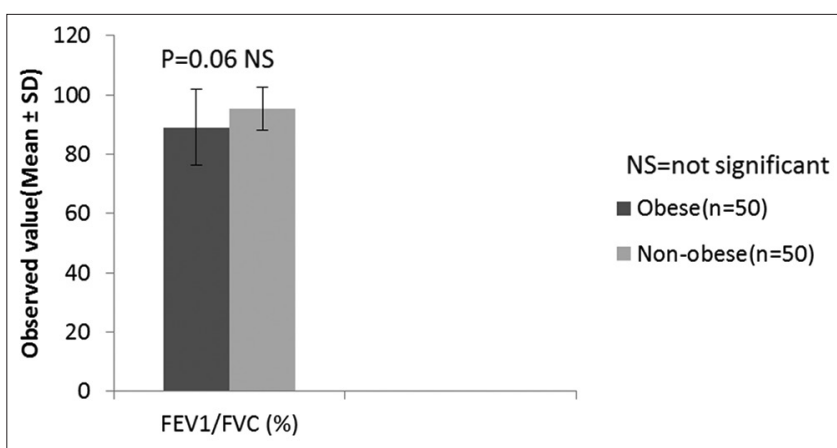

Fig. 1: Comparison of forced expiratory volume 1 /forced vital capacity ratio between obese and non-obese (control group) healthy female of Shah Alam, Malaysia

The mean FVC (L), FEV1 (L), FEF 25-75\% (L/s), and PEFR (L/s) of obese subjects were lower than non-obese control group, but the differences were not significant (Fig. 2)

Table 3 depicts the correlation between different anthropometric obesity markers with dynamic lung function measurements in obese female. Based on correlation coefficient values and $\mathrm{p}$ values, WC and WHR had significant inverse correlation with FVC, FEV1, FEF 25-75\%, and PEFR in obese female, indicating the impairments of pulmonary function with increasing central obesity. However, BMI, which is the indicator of relative or overall obesity had no significant association with any dynamic pulmonary functions.

Table 4 presents the correlation between different anthropometric obesity indices with dynamic lung function measurements in non-obese normal weight female. In normal weight control group, BMI exhibited a significant negative correlation with FEV1/FVC\%, FEF 25-75\%, and 
PEFR, whereas WHR had significant inverse correlation with FVC and FEV1. However, HC exhibited a significant positive correlation with FEV1 and FEF 25-75\% in normal-weight control subjects.

\section{DISCUSSION}

In the global context, many countries, especially in Asia, obesity has become a leading health issue. Urbanization has positive significant impact on the prevalence of obesity [19]. Physical inactivity is the important contributing factor for the prevalence of obesity among young adult female students [20]. One recent study by San et al. [21] revealed that unhealthy food habit such as intake of frequent fast food is associated with the prevalence of obesity among Malaysian adult. Many physiological factors affect lung function. The effect of age, gender, ethnicity, and smoking status on lung function has been confirmed [22,23]. The effects of obesity on spirometric values are not consistent. Some studies showing no effects $[24,25]$ and some other studies showing significant effects [7,26-28]. By this study, we tried to evaluate the effect of obesity on different dynamic pulmonary functions among Malaysian non-smoker healthy adult female university students by comparing lung function of the obese (BMI $>30 \mathrm{~kg} / \mathrm{m}^{2}$ ) to their age matching normal weight control group (BMI $18.5-24.99 \mathrm{~kg} / \mathrm{m}^{2}$ ). Our study showed that the mean FVC (L), FEV1 (L), FEV1/FVC ratio, FEF $25-75 \%(\mathrm{~L} / \mathrm{s})$, and PEFR (L/s) of obese subjects were somewhat lower

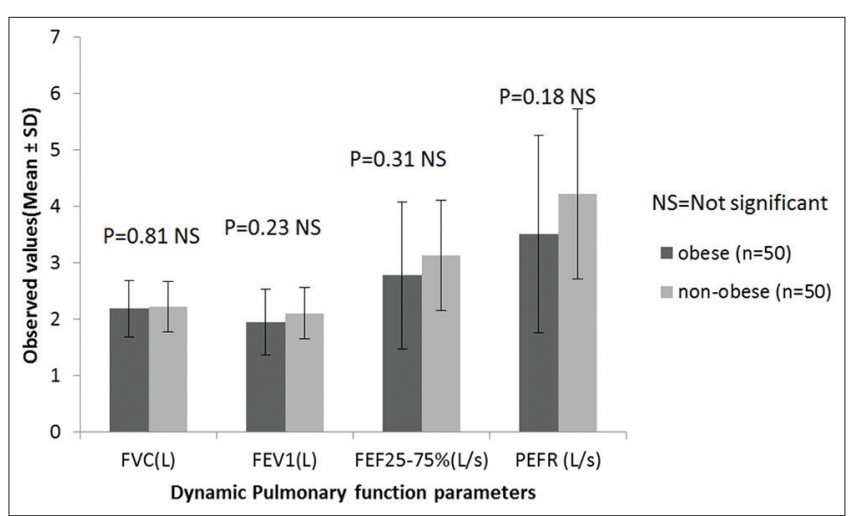

Fig. 2: Comparison of dynamic lung function parameters between obese and non-obese (control group) healthy female of Shah Alam, Malaysia than non-obese control group, but the differences were not statistically significant. This may suggest that obesity has no such adverse effect on dynamic lung function parameters in the studied Malaysian females. Our observation was supported by a study by Al Ghobain [26] conducted on Saudi population where he showed that there were no significant differences between the obese and non-obese subjects in FEV1, FVC, FEV1/FVC ratio, and FEF 25-75\%. Carey et al. [29] showed a reduction in FEV1 but not FVC in obese individual, whereas similar other studies $[30,31]$ showed a decline in both FEV1 and FVC in obese individuals. This discrepancy between studies regarding the effect of obesity on pulmonary function may be explained by the wide variations in ethnicity of different population in PFT values, or this may be a result of methodological differences in these studies.

Most of the previous studies reported an inverse relation between respiratory function and various indices of obesity [10,29-33]. Central obesity (abdominal and thoracic fat) is likely to have direct effects on the pulmonary function, whereas peripheral obesity (the fat on the hips and thighs) would be less likely to have any direct mechanical effect on the lungs. In our study, we investigated the association between adiposity markers with pulmonary function measurements in non-smoker healthy young university girls. In obese girls, WC and WHR exhibited strong significant inverse correlation with all pulmonary function measurements except FEV1/FVC\%, whereas BMI had no significant association with any pulmonary function parameters, suggesting that central obesity has more impact on impairment of dynamic lung function than overall relative obesity. Our findings support the hypothesis that abdominal adiposity markers have better explanatory power than total body adiposity measured as BMI according to $\mathrm{p}$ value significance and the correlation coefficient values. Similar findings were observed by Banerjee et al. [11] where there was no significant association between BMI and lung function parameters (FVC, FEV1, FEV1/FVC, and FEF 25-75\%) in obese male non-asthmatic subjects in India. Our results were consistent with finding by Chen et al. [34] where WC was inversely associated with FVC and FEV1. In our study, we found that central obesity markers are better predictor of lung function than BMI, which is supported by a study [35] in Western New York where they found that WC was a better predictor of pulmonary function than BMI. BMI is not an ideal measure for obesity as a predictor of pulmonary function because of two reasons. First, a higher BMI value for non-obese persons than for obese persons may result from more muscle mass than fat mass (FM). Second, BMI is calculated from body weight and height, which are correlated with body size - the larger the body size, the

Table 3: Correlation of anthropometric obesity indices with pulmonary function measurements in obese female (n=50)

\begin{tabular}{|c|c|c|c|c|c|c|c|c|}
\hline \multirow[t]{2}{*}{ PFT parameters } & \multicolumn{2}{|c|}{ BMI $\left(\mathrm{kg} / \mathrm{m}^{2}\right)$} & \multicolumn{2}{|l|}{ WC (cm) } & \multicolumn{2}{|l|}{$\mathrm{HC}(\mathrm{cm})$} & \multicolumn{2}{|l|}{ WHR } \\
\hline & r values & p values & r values & p values & r values & p values & r values & p values \\
\hline FVC (L) & $0.08 !$ & 0.58 & $-0.50 * *$ & 0.00 & $-0.05 !$ & 0.73 & $-0.35^{*}$ & 0.01 \\
\hline FEV1 (L) & $-0.07 !$ & 0.62 & $-0.46^{* *}$ & 0.00 & $-0.01 !$ & 0.94 & $-0.35^{*}$ & 0.01 \\
\hline FEV1/FVC (\%) & $-0.25 !$ & 0.07 & $-0.08 !$ & 0.58 & $0.06 !$ & 0.67 & $-0.11 !$ & 0.44 \\
\hline FEF $25-75 \%(\mathrm{~L} / \mathrm{s})$ & $-0.19 !$ & 0.18 & $-0.32^{*}$ & 0.02 & $0.03 !$ & 0.83 & $-0.28 *$ & 0.04 \\
\hline PEFR (L/s) & $-0.23 !$ & 0.10 & $-0.28^{*}$ & 0.04 & $0.08 !$ & 0.58 & $-0.29 *$ & 0.04 \\
\hline
\end{tabular}

**Highly significant $\mathrm{P}<0.001$, *mild significant $\mathrm{P}<0.05$, !: Not significant, r: Correlation coefficient, FVC: Forced vital capacity, FEV1: Forced expiratory volume in $1 \mathrm{~s}$, PEFR: Peak expiratory flow rate

Table 4: Correlation of anthropometric obesity indices with pulmonary function measurements in non-obese female (n=50)

\begin{tabular}{|c|c|c|c|c|c|c|c|c|}
\hline \multirow[t]{2}{*}{ PFT parameters } & \multicolumn{2}{|c|}{ BMI $\left(\mathrm{kg} / \mathrm{m}^{2}\right)$} & \multicolumn{2}{|l|}{ WC (cm) } & \multicolumn{2}{|l|}{$\mathrm{HC}(\mathrm{cm})$} & \multicolumn{2}{|l|}{ WHR } \\
\hline & $r$ values & p values & r values & $p$ values & r values & $p$ values & $r$ values & $p$ values \\
\hline FVC (L) & $0.04 !$ & 0.78 & $-0.03 !$ & 0.83 & $0.25 !$ & 0.07 & $-0.34^{*}$ & 0.01 \\
\hline FEV1/FVC (\%) & $-0.50 * *$ & 0.00 & $0.23 !$ & 0.10 & $0.23 !$ & 0.10 & $0.09 !$ & 0.53 \\
\hline $\mathrm{FEF}_{25-75 \%}(\mathrm{~L} / \mathrm{s})$ & $-0.28^{*}$ & 0.04 & $0.20 !$ & 0.16 & $0.44^{* *}$ & 0.00 & $-0.17 !$ & 0.23 \\
\hline PEFR $(\mathrm{L} / \mathrm{s})$ & $-0.35^{*}$ & 0.01 & $0.04 !$ & 0.78 & $0.23 !$ & 0.10 & $-0.19 !$ & 0.18 \\
\hline
\end{tabular}

**Highly significant $\mathrm{P}<0.001, *$ mild significant $\mathrm{P}<0.05$, !: Not significant, r: Correlation coefficient, FVC: Forced vital capacity, FEV1: Forced expiratory volume in $1 \mathrm{~s}$,

PEFR: Peak expiratory flow rate 
greater the PFT variables. The impairment of pulmonary function by abdominal obesity may be explained by some proposed mechanisms. One possible mechanism for the association of abdominal adiposity and pulmonary function is a mechanical limitation of chest expansion during the FVC maneuver. Increased abdominal mass may impede the descent of the diaphragm and increase thoracic pressure [36]. Our findings have similarity with findings of Saxena et al. [12] where they showed abdominal adiposity markers such as WHR and WC had strong negative correlation with FEV1. Pouliot et al. also showed that abdominal adiposity markers have much better explanatory power than total body adiposity measured as BMI [37].

\section{Limitation}

There are few limitations in our study. A bigger sample size would have given more concrete evidence. In our study, we have only investigated the dynamic lung volumes; we did not examine static lung volumes. FM and $\mathrm{BF} \%$ and conicity index (CI) were not determined as measure of obesity.

\section{CONCLUSION}

Our study showed that there was no significant difference in dynamic pulmonary functions among obese and normal weight non-smoker healthy studied females. This may suggest that obesity has no such adverse effect on dynamic lung function parameters on studied females. WC and WHR exhibited highly significant inverse correlation with all pulmonary function measurements except FEV1/FVC\%; however, BMI had no significant correlation with any spirometric variables in obese females, suggesting that central obesity has more impact on impairment of dynamic lung function than overall relative obesity. However, random clinical trials must be conducted with the objective of identifying the repercussions of overweight for lung function. Consequently, it is necessary to implement health-care programs for this population, with the purpose of improving lung function and therefore improving the quality of life of obese individuals.

\section{ACKNOWLEDGMENT}

The authors express gratitude to the study participants for their involvement in the study.

\section{CONFLICTS OF INTEREST}

The authors declare that they have no conflicts of interest.

\section{AUTHOR'S CONTRIBUTION}

Study conception and design: AB; acquisition of data: AT and SR; analysis and interpretation of data: $\mathrm{AB}$ and $\mathrm{AT}$; and drafting of manuscript: Critical revision: $\mathrm{AB}$ and $\mathrm{SR}$

\section{REFERENCES}

1. Lim KG. A review of adult obesity research in Malaysia. Med J Malaysia 2016;71:1-9.

2. Ng M, Fleming T, Robinson M, Thomson B, Graetz N, Margono C, et al. Global, regional, and national prevalence of overweight and obesity in children and adults during 1980-2013: A systematic analysis for the global burden of disease study 2013. Lancet 2014;384:766-81.

3. Institute for Public Health (IPH) National Health and Morbidity Survey 2011 (NHMS 2011). Vol. II: Non-Communicable Diseases. Kuala Lumpur: Ministry of Health Malaysia; 2011.

4. Institute for Public Health (IPH) National Health and Morbidity Survey 2015 (NHMS 2015). Vol. II: Non-Communicable Diseases, Risk Factors and Other Health Problems. Kuala Lumpur: Ministry of Health Malaysia; 2015

5. Obesity: Preventing and managing the global epidemic. Report of a WHO consultation. World Health Organ Tech Rep Ser 2000;894:i-xii, $1-253$.

6. Bai J, Peat JK, Berry G, Marks GB, Woolcock AJ. Questionnaire items that predict asthma and other respiratory conditions in adults. Chest 1998;114:1343-8.

7. Jones RL, Nzekwu MM. The effects of body mass index on lung volumes. Chest 2006;130:827-33.

8. Suratt PM, Wilhoit SC, Hsiao HS, Atkinson RL, Rochester DF. Compliance of chest wall in obese subjects. J Appl Physiol Respir Environ Exerc Physiol 1984;57:403-7.

9. Lazarus R, Sparrow D, Weiss ST. Effects of obesity and fat distribution on ventilatory function: The normative aging study. Chest 1997; 111:891-8

10. Chen Y, Horne SL, Dosman JA. Body weight and weight gain related to pulmonary function decline in adults: A six year follow up study. Thorax 1993;48:375-80.

11. Banerjee J, Roy A, Singhamahapatra A, Dey PK, Ghosal A, Das A. Association of body mass index (BMI) with lung function parameters in non-asthmatics identified by spirometric protocols. J Clin Diagn Res 2014;8:12-4

12. Saxena Y, Sidhwani G, Upmanyu R. Abdominal obesity and pulmonary functions in young Indian adults: A prospective study. Indian J Physiol Pharmacol 2009;53:318-26.

13. Bhattacharjee A, Thygoo A, Rammohan S. Obesity and pulmonary functions in young non smoker male of Shahalam, Malaysia. Indian J Public Health Res Dev 2018(accepted for publication).

14. World Health Organization (WHO). BMI classification. Genebra: WHO; 2011.

15. American Thoracic Society. Standard questionnaires on respiratory symptoms, tests of pulmonary function, and chest radiographs. Am Rev Respir Dis 1978;118:10-23.

16. VanderJagt DJ, Trujillo MR, Jalo I, Bode-Thomas F, Glew RH, Agaba $\mathrm{P}$, et al. Pulmonary function correlates with body composition in Nigerian children and young adults with sickle cell disease. J Trop Pediatr 2008;54:87-93

17. Hetzel MR. The pulmonary clock. Thorax 1981;36:481-6.

18. Chatterjee S, Mandal A. Pulmonary function studies in healthy school boys of west bengal. Jpn J Physiol 1991;41:797-808.

19. Thapliyal V, Singh K, Joshi A. Catastropic shift of obesity in three zones of sub-Himalayan region, India and its correlation with the dietary intake. Asian J Pharm Clin Res 2018;11:404-8.

20. Anitha M, Monisha DM, Chella KJ. Prevalence of obesity and overweight among medicos in both male and female students. Asian J Pharm Clin Res 2016;9:289-91.

21. San O, Rao M, Zin T. Prevalence and factors associated with obesity among adult at the Kampong Kolam, East Coast Malaysian peninsula-a cross sectional study. Int J Pharm PharmSci 2017;9:273-81.

22. Crapo RO, Jensen RL. Standards and interpretive issues in lung function testing. Respir Care 2003;48:764-72.

23. Pelzer AM, Thomson ML. Effect of age, sex, stature, and smoking habits on human airway conductance. J Appl Physiol 1966;21:469-76.

24. Jenkins SC, Moxham J. The effects of mild obesity on lung function. Respir Med 1991;85:309-11.

25. Sutherland TJ, Cowan JO, Young S, Goulding A, Grant AM, Williamson A, et al. The association between obesity and asthma: Interactions between systemic and airway inflammation. Am J Respir Crit Care Med 2008; 178:469-75

26. Al Ghobain M. The effect of obesity on spirometry tests among healthy non-smoking adults. BMC Pulm Med 2012;12:10.

27. Watson RA, Pride NB. Postural changes in lung volumes and respiratory resistance in subjects with obesity. J Appl Physiol (1985) 2005;98:512-7.

28. Salome CM, King GG, Berend N. Physiology of obesity and effects on lung function. J Appl Physiol (1985) 2010;108:206-11.

29. Carey IM, Cook DG, Strachan DP. The effects of adiposity and weight change on forced expiratory volume decline in a longitudinal study of adults. Int J Obes Relat Metab Disord 1999;23:979-85.

30. Steele RM, Finucane FM, Griffin SJ, Wareham NJ, Ekelund U. Obesity is associated with altered lung function independently of physical activity and fitness. Obesity (Silver Spring) 2009;17:578-84.

31. Canoy D, Luben R, Welch A, Bingham S, Wareham N, Day N, et al. Abdominal obesity and respiratory function in men and women in the EPIC-norfolk study, united kingdom. Am J Epidemiol 2004;159:1140-9.

32. Chinn DJ, Cotes JE, Reed JW. Longitudinal effects of change in body mass on measurements of ventilatory capacity. Thorax 1996;51:699-704.

33. Ray CS, Sue DY, Bray G, Hansen JE, Wasserman K. Effects of obesity on respiratory function. Am Rev Respir Dis 1983;128:501-6.

34. Chen Y, Rennie D, Cormier YF, Dosman J. Waist circumference is associated with pulmonary function in normal-weight, overweight, and obese subjects. Am J Clin Nutr 2007;85:35-9.

35. Ochs-Balcom HM, Grant BJ, Muti P, Sempos CT, Freudenheim JL, 
Trevisan M, et al. Pulmonary function and abdominal adiposity in the general population. Chest 2006;129:853-62.

36. Sugerman H, Windsor A, Bessos M, Wolfe L. Intra-abdominal pressure, sagittal abdominal diameter and obesity comorbidity. J Intern Med 1997;241:71-9.
37. Pouliot MC, Després JP, Lemieux S, Moorjani S, Bouchard C, Tremblay A, et al. Waist circumference and abdominal sagittal diameter: Best simple anthropometric indexes of abdominal visceral adipose tissue accumulation and related cardiovascular risk in men and women. Am J Cardiol 1994;73:460-8. 